\title{
Mesothelioma incidence projections in South East England
}

\author{
Sharma P. Riaz*, Victoria H. Coupland*, Margreet Lüchtenborg*, \\ Michael D. Peake ${ }^{\#}$ and Henrik Møller*
}

ABSTRACT: We estimated the past and future age-standardised incidence rates of mesothelioma
by birth cohort and by period of diagnosis in South East England.

We extracted data on patients diagnosed with mesothelioma (International Classification of Diseases-10 C45) between 1960 and 2009 from the Thames Cancer Registry. We calculated the age-standardised incidence rates using the European standard population. We used age-cohort and age-period modelling to estimate the age-specific incidence rates for the 1900 to 1950 birth cohorts and the 1935 to 2034 calendar periods.

A much more pronounced increase in mesothelioma incidence between 1972 and 2007 was observed in males than in females. In both sexes, the incidence rates increased in successive generations up to the $\mathbf{1 9 4 5}$ birth cohort. Projection of rates in the future showed an increase in incidence in males until 2022 and a decrease thereafter. Among females, the incidence rate was predicted to increase gradually until reaching its maximum around 2027, and to remain stable thereafter.

The occurrence of mesothelioma is closely linked to occupational exposure to asbestos in the 1960 s and 1970s and, due to the long latency period, the incidence of mesothelioma is projected to increase until the 2020s.

KEYWORDS: Asbestos, incidence, mesothelioma, pleural mesothelioma, projections

$\mathbf{P}$ leural mesothelioma is a malignant tumour of the membrane surrounding the lung. It is currently considered an incurable tumour with a median survival approaching 1 yr. [1]

The leading cause of mesothelioma is occupational exposure to asbestos fibres. Asbestos was widely used in many industries in the UK from the 1950s up until the mid-1980s. In the earlier part of this period, asbestos exposure occurred most commonly in mining, ship building, and manufacturing of asbestos textiles and cement, but in the later period those working in plumbing, insulation, demolition and construction industries became the largest at-risk group. The importance of the low levels of "ambient" asbestos in many public and private buildings from the 1950s and 1960s is unknown.

The incidence of mesothelioma started to increase in the 1970s. The number of new cases of mesothelioma diagnosed in the UK in 2008 was $\sim 2,400$ and is expected to rise in subsequent years [2]. Previous predictions of future numbers of mesothelioma deaths in the UK suggest that male mesothelioma deaths would peak at around the year 2020 [3].
In South East England, 440 cases of mesothelioma were diagnosed in the most recent year. The relatively high number of mesothelioma cases in South East England compared with the UK overall is probably due to the high exposure to asbestos in the ship-building industry [1]. We aimed to project the past and future incidence rates by birth cohort and by period of diagnosis among males and females in South East England.

\section{METHODS}

\section{Study population}

From the Thames Cancer Registry (TCR) database, we identified 8,250 patients diagnosed with mesothelioma (International Classification of Diseases10 C45) between 1960 and 2009 [4]. The TCR is one of 12 population-based cancer registries in the UK and covers the residential populations of London, Surrey, Sussex and Kent. In this area, registration is initiated by pathology and clinical information received from hospitals. Trained cancer registration officers seek additional information from the medical records on demographic details, disease stage and treatment. Data are quality assured when added to a central database and updated continuously.

\section{AFFILIATIONS}

*King's College London, Thames

Cancer Registry, London, and

\#Dept of Respiratory Medicine,

Glenfield Hospital, Leicester, UK.

CORRESPONDENCE

S.P. Riaz

King's College London

Thames Cancer Registry

1st Floor

Capital House

42 Weston Street

UK, London SE1 3QD, UK

E-mail: sharma.riaz@kcl.ac.uk

Received:

Sept 282011

Accepted after revision:

Dec 222011

First published online:

Jan 262012 


\begin{tabular}{|c|c|c|c|c|c|}
\hline \multirow[t]{2}{*}{ Period } & \multicolumn{2}{|c|}{ Males } & \multicolumn{2}{|c|}{ Females } & \multirow[t]{2}{*}{ Male:female incidence ratio } \\
\hline & Cases $\mathrm{n}$ & ASR $(95 \% \mathrm{Cl})$ & Cases $\mathrm{n}$ & ASR $(95 \% \mathrm{Cl})$ & \\
\hline 1962 & 8 & $0.05(0.02-0.09)$ & 5 & $0.02(0.00-0.04)$ & 2.34 \\
\hline 1977 & 162 & $0.97(0.82-1.12)$ & 44 & $0.20(0.14-0.26)$ & 4.89 \\
\hline 1982 & 262 & $1.56(1.37-1.75)$ & 53 & $0.24(0.18-0.31)$ & 6.41 \\
\hline 1987 & 753 & $2.79(2.58-2.99)$ & 155 & $0.43(0.36-0.50)$ & 6.47 \\
\hline 1992 & 954 & $3.56(3.33-3.79)$ & 201 & $0.59(0.50-0.68)$ & 6.06 \\
\hline 1997 & 1151 & $4.16(3.92-4.41)$ & 222 & $0.62(0.53-0.71)$ & 6.69 \\
\hline
\end{tabular}

\section{Statistical analysis}

For the analyses, age at diagnosis was categorised into 5-yr age groups with the mid-point representing the group, for example, 0-5-yr-olds were represented by " 2 ", and hence age groups were 2,7 , etc., through to 87 (85+ yrs). We categorised the year of diagnosis into 5-yr periods, which were represented by the mid-points of 1962 (for 1960-1964), 1977 etc., through to 2007. We assumed that the age-specific incidence rates were constant for patients younger than $27 \mathrm{yrs}$ of age, extrapolating their 1962 rates backwards and their 2007 rates forwards in time. We used a Poisson regression age cohort model [5] to estimate age-specific rates in the cohort dimension and an age-period model to extrapolate in the period dimension. We then calculated the age-standardised rates (per 100,000 European standard population) for birth cohorts and cross-sectionally for the different calendar periods. Because the earlier and later cohort estimates were based on a small number of cases, and were therefore less robust, we report estimates for the 1900 to 1950 birth cohorts and the 1960 to 2009 calendar periods.

\section{Ethics}

Cancer registries in England have approval from the National Information Governance Board to carry out surveillance using the data they collect on all cancer patients under section 251 of the National Health Service Act of 2006. Therefore, separate ethical approval was not required for this study.

\section{RESULTS}

The age-standardised incidence rates of mesothelioma were higher among males than females (table 1 and fig. 1). The male/ female incidence ratio changed from 2:1 in 1962 to 6:1 in the 1980s and 1990s, falling back to 5:1 in the 2000s (table 1 and fig. 1). Incidence rates increased from 1962 to 2007 (table 1). This increase occurred more rapidly among males (0.05 in 1962 to 5.52 in 2007) and more gradually in females (0.02 in 1962 to 1.13 in 2007).

First, an age-cohort Poisson regression model was fitted to the empirical data, where the response variable was the number of recorded diagnoses, the age group at diagnosis and birth cohort were treated as explanatory variables, and the logarithm of the population at risk was included as the offset term in the model.
The age-standardised incidence rates increased in successive generations up to the 1945 cohort when the estimated incidence rates were 9.04 per 100,000 among males and 1.96 per 100,000 among females (fig. 2). The incidence rate decreased in the generation born after 1945 .

Secondly, the estimated rates from the age-cohort model were combined with the empirical data to form the input to an ageperiod Poisson regression model. This model was specified in the same way as the age-cohort model but with birth cohort replaced by period of diagnosis. We projected that the incidence rates in males will increase until the 2020s and decrease thereafter (fig. 3). Among females, the incidence rates were projected to increase gradually until reaching a peak in the late 2020s and remaining relatively stable thereafter. Projections further into the future became less robust.

\section{DISCUSSION}

The relatively high incidence of mesothelioma in the area covered by the TCR is probably due to the occupational exposure to asbestos particularly in the ship-building industries present in

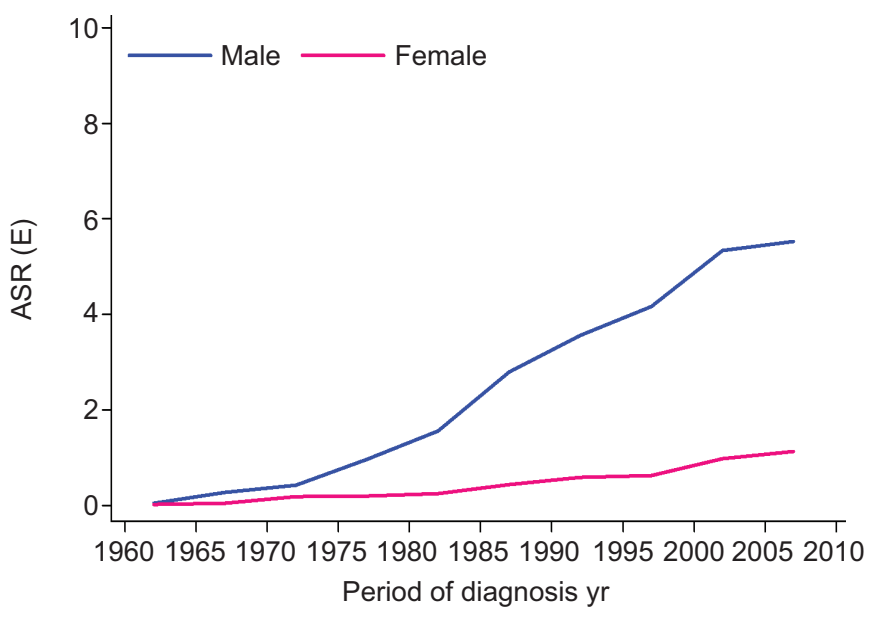

FIGURE 1. Age-standardised incidence rates per 100,000 European standard population (ASR (E)) per 100,000 of mesothelioma, by sex and period of diagnosis, South East England, 1962-2007. 


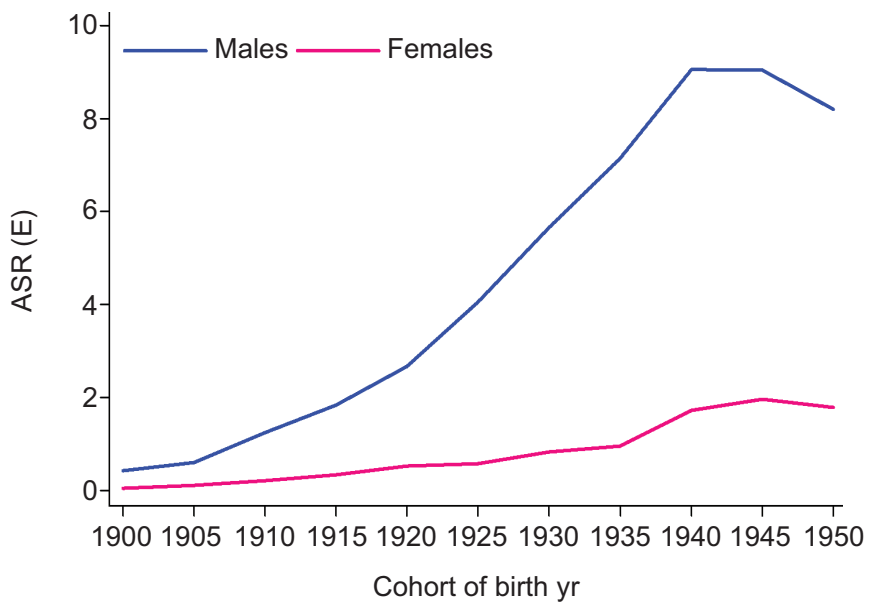

FIGURE 2. Age-standardised incidence rates per 100,000 European standard population (ASR (E)) of mesothelioma by sex and cohort of birth, South East England, 1900-1950.

South East England and thereby affecting mostly males [6] Mesothelioma incidence rates were found to be higher among males than females. This is in accordance with other studies in the UK $[1,2]$ and around the world [7-11]. The male preponderance is contrasted by a follow-up study of a rural Turkish cohort, which found a higher incidence of mesothelioma in females than males [12]. People in this cohort were exposed from birth to asbestos-containing soil mixtures ("white soil"). White soil was used in whitewash or plaster materials for walls; as insulation and water proofing; for floors and roofs; for baby powder and also in pottery.

A British study published in 1995 reported a peak in imported asbestos between the 1960s and 1970s [3]. The use of blue and brown asbestos was banned in the UK in 1985. Given the estimated median induction time of 32 yrs for occupation-related mesothelioma [13], this would explain both our observation of the rapid increase in incidence rates in the calendar periods 1972 to 2007 , as well as the high incidence rates of mesothelioma among generations born up to the 1945 birth cohort and the decreasing incidence in the birth cohorts thereafter.

Incidence rates in males were projected to increase in each period until about 2022 and to decrease thereafter, whereas, in females, the incidence rates are estimated to peak around 2027. In general, using age-period-cohort modelling, studies around the world project fairly similar timing of peak incidence. A study in Denmark also predicted the future annual number of mesothelioma cases to peak around 2015 or later [14]. A study conducted in France predicted a much later peak in mortality between 2025 and 2050, which is related to the later peak in French import of asbestos in 1975 [15]. A recent USA study reported significantly increased mesothelioma incidence from the late 1970s through to the mid-1990s, and projections in this study indicate that the number of male mesothelioma cases peaked during 2000-2004 [16]. An early peak in the USA compared with the UK is due to the timing of maximum exposure, where a maximum exposure in the USA occurred from the 1930s to the 1960s [17]. Workers born after 1929 would have had fewer years of exposure to asbestos, hence the earlier decline in mesothelioma cases.

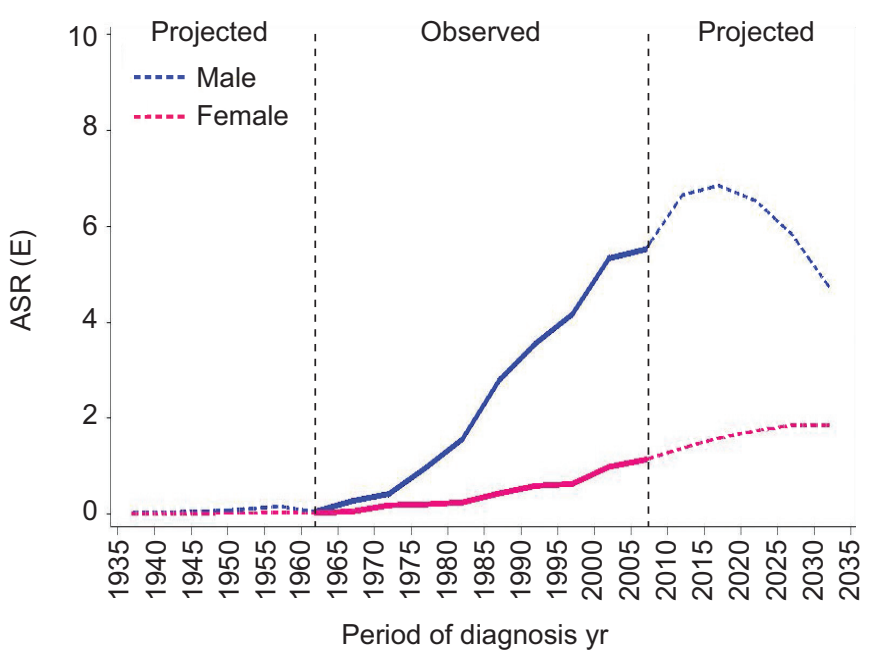

FIGURE 3. Observed and projected age-standardised incidence rates per 100,000 European standard population (ASR (E)) of mesothelioma by sex and period of diagnosis, South East England, 1935-2032.

A previous UK study projected the peak in the number of deaths due to mesothelioma to occur in 2020, which is slightly earlier compared with the projections in our study [3]. More recent publications from the same group predicted the peak of mesothelioma deaths to occur a further 5 yrs earlier $[18,19]$. In these latter two studies, the estimated population exposure to asbestos was included in the model for prediction of mesothelioma mortality. A study in Australia applying both modelling approaches projected the mesothelioma incidence to peak between 2014 and 2021, where the age-period-cohort model projected a later incidence peak than the model that incorporated projections based also on asbestos exposure [20]. Analyses that base the projection on the modelling of exposure to asbestos in the population on assumptions about distribution, dose and dose rates of the exposure may not be very accurate, especially in the period after the import of asbestos had stopped. The age-period-cohort modelling used in this study allows for separate effects of age, calendar period and birth cohort. It does not take into account any available data on asbestos exposure in the population, but allows indirectly for this through the impact of this exposure on the empirical mesothelioma rates. We consider that both strategies of analysis have merits and we note that the predictions of future disease pattern are in general agreement.

\section{Conclusion}

We project that the incidence rates of mesothelioma in South East England will continue to increase and will peak in the 2020s, and at a slightly later time for females than for males.

\section{SUPPORT STATEMENT}

The Thames Cancer Registry in King's College London receives funding from the Department of Health for England. The views expressed in the article are those of the authors and not necessarily those of the Department of Health.

\section{STATEMENT OF INTEREST}

None declared. 


\section{ACKNOWLEDGEMENTS}

This paper is a contribution from the National Cancer Intelligence Network (www.ukacr.org; www.ncin.org.uk).

\section{REFERENCES}

1 Mak V, Davies E, Putcha V, et al. The epidemiology and treatment of mesothelioma in South East England 1985-2002. Thorax 2008; 63: 160-166.

2 UK CR. Mesothelioma statistics - key facts. http://info.cancerresearchuk.org/cancerstats/types/Mesothelioma/ Date last updated: November 29, 2010. Date last accessed: June 18, 2012.

3 Peto J, Hodgson JT, Matthews FE, et al. Continuing increase in mesothelioma mortality in Britain. Lancet 1995; 345: 535-539.

4 World Health Organisation. International Statistical Classification of Disease (ICD-10) and Related Health Problems. 2nd Edn. Geneva, Switzerland, 2004; pp. 185-186.

5 Clayton D, Schifflers E. Models for temporal variation in cancer rates. II: age-period-cohort models. Stat Med 1987; 6: 469-481.

6 Yates DH, Corrin B, Stidolph PN, et al. Malignant mesothelioma in south east England: clinicopathological experience of 272 cases. Thorax 1997; 52: 507-512.

7 Weill H, Hughes JM, Churg AM. Changing trends in US mesothelioma incidence. Occup Environ Med 2004; 61: 438-441.

8 Mesothelioma in Australia. Incidence 1982 to 2004. Deaths 1997 to 2005. Australian Safety and Compensation Council. http:/ / safeworkaus tralia.gov.au/AboutSafeWorkAustralia/WhatWeDo/Publications / Documents/192/MesotheliomaInAustralia_Incidence1982_2004_ Deaths_1997_2005_PDF.pdf Date last accessed: June 18, 2012.
9 Jarvholm B, Englund A, Albin M. Pleural mesothelioma in Sweden: an analysis of the incidence according to the use of asbestos. Occup Environ Med 1999; 56: 110-113.

10 Kanazawa N, Ioka A, Tsukuma H, et al. Incidence and survival of mesothelioma in Osaka, Japan. Jpn J Clin Oncol 2006; 36: 254-257.

11 Andersson M, Olsen JH. Trend and distribution of mesothelioma in Denmark. Br J Cancer 1985; 51: 699-705.

12 Metintas S, Metintas M, Ucgun I, et al. Malignant mesothelioma due to environmental exposure to asbestos: follow-up of a Turkish cohort living in a rural area. Chest 2002; 122: 2224-2229.

13 Lanphear BP, Buncher CR. Latent period for malignant mesothelioma of occupational origin. J Occup Med 1992; 34: 718-721.

14 Kjaergaard J, Andersson M. Incidence rates of malignant mesothelioma in Denmark and predicted future number of cases among men. Scand J Work Environ Health 2000; 26: 112-117.

15 Banaei A, Auvert B, Goldberg M, et al. Future trends in mortality of French men from mesothelioma. Occup Environ Med 2000; 57: 488-494.

16 Price B, Ware A. Mesothelioma trends in the United States: an update based on Surveillance, Epidemiology, and End Results Program data for 1973 through 2003. Am J Epidemiol 2004; 159: 107-112.

17 Price B. Analysis of current trends in United States mesothelioma incidence. Am J Epidemiol 1997; 145: 211-218.

18 Hodgson JT, McElvenny DM, Darnton AJ, et al. The expected burden of mesothelioma mortality in Great Britain from 2002 to 2050. Br J Cancer 2005; 92: 587-593.

19 Tan E, Warren N, Darnton AJ, et al. Projection of mesothelioma mortality in Britain using Bayesian methods. Br J Cancer 2010; 103: 430-436.

20 Clements M, Berry G, Shi J, et al. Projected mesothelioma incidence in men in New South Wales. Occup Environ Med 2007; 64: 747-752. 